\title{
Drinking Amount Associated with Abnormal Gamma-Glutamyl Transpeptidase Expression in Women
}

\author{
Jun-Seok Yang, Jong-Sung Kim*, Won-Yoon Seo, Sir-Chae Paik \\ Department of Family Medicine, Research Institute for Medical Sciences, Chungnam National University School of Medicine, Daejeon, Korea
}

Background: This study investigated whether there is any difference in drinking amount associated with abnormal expression of gamma-glutamyl transpeptidase (GGT), one of the biological markers of excessive drinking, between flushing and non-flushing women after drinking

Methods: The subjects were 797 women aged 20-59 years old who visited health promotion center of Chungnam National University Hospital between January, 2013 and July, 2014. Facial flushing status after drinking, amount of alcohol consumed per drinking episode, and the number of drinking days per week were assessed using a questionnaire. Age, abnormal GGT expression, smoking status, menopauase status, and body mass index (BMI) were obtained from the health screening data. The weekly drinking amount were categorized into $<4$ drinks; $\geq 4,<8$ drinks; and $\geq 8$ drinks. The association of abnormal GGT expression with weekly drinking amount was analyzed using multivariate logistic regression after controlling for confounding variables including age, smoking status, menopauase status, and BMI.

Results: Compared to nondrinkers, the abnormal GGT expression in the non-flushing group was significantly increased when the weekly drinking amount was $\geq 4$ drinks ( $\geq 4,<8$ drinks: adjusted odds ratio [aOR], 37.568; 95\% confidence interval [CI], 9.793-144.116; $\geq 8$ drinks: aOR, 20.350; 95\% CI, 20.350-305.138). On the other hand, the abnormal GGT expression in the flushing group was significantly increased in every weekly drinking amount range ( $<4$ drinks: aOR, 4.120; 95\% CI, 1.603-10.585; $\geq 4$, < 8 drinks: aOR, 79.206; 95\% CI, 24.034-261.031; $\geq 8$ drinks: aOR, 111.342; 95\% CI, 30.987-400.079). For each weekly drinking amount range, the flushing group showed significantly higher abnormal GGT expression than the non-flushing group ( $<4$ drinks: aOR, 3.867; 95\% CI, 1.786-8.374; $\geq 4,<8$ drinks: aOR, 57.277; 95\% CI, 24.430-134.285; $\geq 8$ drinks: aOR, 104.871; 95\% CI, 42.945-256.091).

Conclusion: This study showed that abnormal GGT expression in the flushing female drinkers was induced by smaller amounts of alcohol than in the non-flushing female drinkers.

Keywords: Flushing; Drinking; Gamma-Glutamyltransferase 


\section{INTRODUCTION}

Reactions to the same amount of alcohol vary by individual and sex. One of the common reactions to drinking is facial flushing, caused mainly by accumulation of acetaldehyde. Genetic polymorphisms in alcohol dehydrogenase $(\mathrm{ADH})$ and aldehyde dehydrogenase (ALDH) are known to affect alcohol metabolism. ${ }^{1)}$ Acetaldehyde metabolism capacity is especially decreased when inactive ALDH2 isoenzyme is expressed, known as the Asian variant. People with the inactive form of the ALDH gene experience symptoms including vasodilation, facial flushing, palpitations, nausea, and vomiting due to accumulation of acetaldehyde after drinking. ${ }^{2)}$ This difference in the capability of acetaldehyde metabolism results in different individual capacities for metabolizing consumed alcohol. ${ }^{3-5)}$ While only $2.9 \%-$ $21.4 \%$ of Westerners show facial flushing after drinking, up to $40 \%-50 \%$ of Asians show facial flushing, ${ }^{6-8)}$ as a significant number of Asians carry the above-mentioned ALDH2 with markedly reduced enzymatic activity. ${ }^{9)}$

As modern women participate more in social activities, and women's awareness and the social codes on drinking, once considered only man's domain, have been changed, the amount and frequency of women's drinking has increased rapidly. ${ }^{10)}$ Women have different drinking behaviors from men. In general, women are older than men when they begin drinking, and they drink smaller quantities and less frequently. Additionally, more women drink alone than men. ${ }^{11,12)}$

Women metabolize alcohol less efficiently than men because of their lower ADH levels, ${ }^{13)}$ and higher body fat content, ${ }^{14)}$ which is why the National Institute on Alcohol Abuse and Alcoholism $(\text { NIAAA })^{15)}$ recommends that women drink $<7$ standard drinks per week, about the half of the recommendation for men. In addition, the risk of fetal alcohol syndrome is representative of the uniqueness of drinking issues in women. Therefore, alcohol problem in women carries the possibility of more serious damage.

Meanwhile, gamma-glutamyl transpeptidase (GGT) is a liver enzyme, the expression of which is increased by blockage of the bile duct, certain drugs, or, especially, alcohol. Moreover, American Psychiatry Association recommends GGT as one of the excessive drinking indicator. ${ }^{16)}$ Since the flushing group after drinking metabolizes less acetaldehyde than the non-flushing group, they are expected to maintain higher blood levels of alcohol and acetaldehyde, resulting in increased abnormal GGT expression. Although there are many reports on the effects of drinking in men, especially on facial flushing, it is difficult to find a report on the relationship between risky drinking amounts and facial flushing in women. Therefore, this study investigated whether there is any difference in the drinking amount related to the GGT abnormality between flushing and non-flushing women after drinking.

\section{METHODS}

\section{Study Subjects}

Among women aged 20-59 years old who were screened at health promotion center of Chungnam National University Hospital between January, 2013 and July, 2014, 797 women were selected as study subjects. Women who were positive on hepatitis B surface antigen or anti hepatitis C virus, or on medications were excluded. There were 356 nondrinkers and 441 drinkers (137 flushers and 304 non-flushers after drinking).

\section{Study Methods}

The subjects' basic data were obtained from retrospective review on the medical records written at the time of comprehensive health examination. The data included age, smoking history, height, weight, menopause status, and body mass index (BMI), which was calculated using height and weight measured at screening. Drinking-related characteristics included the single episode drinking amount for the past year, the weekly drinking frequency, and facial flushing status after drinking. For drinking amounts, $14 \mathrm{~g}$ of alcohol was converted to ' 1 standard drink' based on the NIAAA guideline. ${ }^{15)}$ The weekly drinking amount was calculated as the product of the weekly drinking frequency and the single episode drinking amount. The status of facial flushing after drinking was responded as 'always flushing,' 'sometimes flushing, or 'never flushing.' Those who responded with 'always flushing' or 'sometimes flushing' were classified into the flushing group, and those who responded with 'never flushing' into the non-flushing group. This classification was based on the study by Yokoyama et al., ${ }^{17)}$ in which facial flushing after drinking was classified as just described above, the sensitivity and specificity for identifying the inactive ALDH2 genotype was $96.1 \%$ and $79.0 \%$, respectively.

\section{Statistics}

With the nondrinking group as the standard, the general characteristics of the flushing and non-flushing groups were compared using chi-square and t-tests. Considering a bottle of soju, the most popular liquor among Koreans, to be equivalent to 4 standard drinks, the weekly drinking amount was divided into $<4$ drinks; $\geq 4,<8$ drinks; and $\geq 8$ drinks. The incidence of subjects with abnormal GGT expression per weekly drinking amount was compared to the incidence in the nondrinking group using the chi-square test. Based on the nondrinkers, the risk for abnormal GGT expression in each weekly drinking amount range was analyzed by logistic regression after controlling for confounding variables including age, smoking status, menopause status, and BMI. In addition, the risk of abnormal GGT expression in the flushing group was analyzed on the basis of non-flushing group. IBM SPSS for Windows ver. 20.0 (IBM Co., Armonk, NY, USA) was used for statistical analysis, and 
$\mathrm{P}<0.05$ was considered significant.

\section{RESULTS}

\section{General Characteristics of the Study Subjects}

The mean \pm standard deviation (SD) age of the nondrinking group was $47.05 \pm 9.12$ years. The mean \pm SD age of the facial flushing and non-flushing group was $44.27 \pm 8.66$ years and $42.94 \pm 9.08$ years, respectively. The age was significantly (both $\mathrm{P}<0.001$ ) lower in both non-flushing and flushing group than the nondrinking group. In addition, compared to the $2.2 \%$ smoking rate in the nondrinking group, the smoking rate was significantly higher in the flushing group $(14.6 \%, \mathrm{P}<0.001)$ and the non-flushing group $(9.5 \%, \mathrm{P}<0.05)$. The menopause rate was significant lower in both flushing group $(24.8 \%, \mathrm{P}<0.05)$ and non-flushing group $(21.05 \%, \mathrm{P}<0.01)$ than nondrinking group (37.1\%). Compared to the nondrinking group, the GGT level was significantly higher in the flushing and the non-flushing group (both $\mathrm{P}<0.001$ ). Neither weight nor $\mathrm{BMI}$ in the flushing and non-flushing group were significantly different from that in the nondrinking group (Table 1).

\section{Risk for Abnormal Gamma-Glutamyl Transpeptidase Expression according to Weekly Drinking Amount in Flushers and Non-Flushers}

In the nondrinking group, $3.4 \%$ of subjects showed abnormal GGT levels. In comparison, the rate of abnormal GGT levels was significantly higher in the flushing group than the nondrinking group in every weekly drinking amount range: $17.3 \%(\mathrm{P}<0.05)$ for the $<4$ drinks range, $79.3 \%(\mathrm{P}<0.01)$ for the $\geq 4,<8$ drinks range, and $81.5 \%$ ( $\mathrm{P}<0.01)$ for the $\geq 8$ drinks range. On the other hand, the abnormal GGT expression rates in the non-flushing group were significantly higher at $\geq 4$ drinks: $34.8 \%(\mathrm{P}<0.01)$ for $\geq 4,<8$ drinks and $48.8 \%(\mathrm{P}<0.01)$ for $\geq 8$ drinks (Table 2). On the basis of nondrinking group, multivariate logistic regression analysis was performed to determine the risk of abnormal GGT expression among the flushing and non-flushing groups, after adjustment for the confounding variables such as age, smoking status, menopause status, and BMI. The risk of abnormal GGT expression was significantly higher in the flushing group across all drinking amount ranges compared to the nondrinking group (<4 drinks: odds ratio [OR], 4.120; 95\% confidence interval [CI], 1.603-10.585; $\geq 4$, <8 drinks: OR, 24.034; 95\% CI, 24.034-261.031; $\geq 8$ drinks: OR, 111.342; 95\% CI, 30.987400.079). The risk of abnormal GGT expression of the non-flushing group was significantly higher than that of the nondrinking group when the drinking amount was $\geq 4$ drinks ( $\geq 4,<8$ drinks: OR, 37.568; 95\% CI, 9.793-144.116; $\geq 8$ drinks: OR, 78.801; 95\% CI, 20.350-305.138) (Table 3).

\section{Comparison of the Risk for Abnormal Gamma-Glutamyl}

Transpeptidase Expression of Flushers and Non-Flushers After adjusting for age, menopause status, smoking status, and $\mathrm{BMI}$, multivariate logistic regression was performed to compare the risk of abnormal GGT expression of the flushing with non-flushing groups. The risk of abnormal GGT expression was significantly higher in the flushing group in every range of the weekly drinking amount than the non-flushing group $(<4$ drinks: OR, 3.867; 95\% CI, 1.786-8.374; $\geq 4$, <8 drinks: OR, 57.277; 95\% CI, 24.430-134.285; $\geq 8$ drinks: OR, 104.871; 95\% CI, 42.945256.091) (Table 4).

Table 2. Abnormal GGT expression according to weekly drinking amount in flushers and non-flushers

\begin{tabular}{lcr}
\hline Variable & $\begin{array}{c}\text { Abnormal GGT expression ratio \% } \\
\text { (abnormal/total) }\end{array}$ & P-value* $^{*}$ \\
\hline Non-drinkers & $3.4(12 / 356)$ & \\
$\begin{array}{l}\text { Flushers (drinks/wk) } \\
<4\end{array}$ & $17.3(14 / 81)$ & 0.033 \\
$4-8$ & $79.3(23 / 29)$ & $<0.001$ \\
$\geq 8$ & $81.5(22 / 27)$ & $<0.001$ \\
Non-flushers (drinks/wk) & & 0.726 \\
$<4$ & $4.1(9 / 215)$ & $<0.001$ \\
$4-8$ & $34.8(16 / 46)$ & $<0.001$ \\
$\geq 8$ & $48.8(21 / 43)$ & \\
\hline
\end{tabular}

GGT, gamma-glutamyl transpeptidase.

${ }^{*}$ Compared with nondrinkers by chi-square test.

Table 1. General characteristics of subjects

\begin{tabular}{|c|c|c|c|c|c|}
\hline \multirow{2}{*}{ Variable } & \multirow{2}{*}{$\begin{array}{l}\text { Nondrinkers } \\
(n=356)\end{array}$} & \multicolumn{4}{|c|}{ Drinkers } \\
\hline & & Flushers $(n=137)$ & P-value ${ }^{\star}$ & Non-flushers $(n=304)$ & P-value* \\
\hline Age (y) & $47.05 \pm 9.12$ & $44.27 \pm 8.66$ & $<0.001$ & $42.94 \pm 9.08$ & $<0.001$ \\
\hline Body weight & $57.46 \pm 8.42$ & $58.45 \pm 8.58$ & 0.233 & $58.17 \pm 8.53$ & 0.499 \\
\hline Body mass index & $22.93 \pm 3.28$ & $23.14 \pm 3.27$ & 0.644 & $22.93 \pm 3.42$ & 0.914 \\
\hline Menopause & $132(37.08)$ & $34(24.82)^{\star}$ & 0.028 & $64(21.05)^{\star}$ & $<0.001$ \\
\hline Smoking & $8(2.19)$ & $20(14.6)^{*}$ & $<0.001$ & $29(9.54)^{*}$ & 0.018 \\
\hline Drink frequency/wk & 0 & $1.64 \pm 2.01$ & $<0.001$ & $1.07 \pm 1.00$ & $<0.001$ \\
\hline Drinks ${ }^{\dagger} /$ time & 0 & $2.80 \pm 2.93$ & $<0.001$ & $2.29 \pm 1.95$ & $<0.001$ \\
\hline Drinks/wk & 0 & $6.89 \pm 17.94$ & $<0.001$ & $3.13 \pm 6.13$ & $<0.001$ \\
\hline Gamma-glutamyl transpeptidase & $12.30 \pm 7.78$ & $46.90 \pm 55.95$ & $<0.001$ & $19.44 \pm 19.81$ & $<0.001$ \\
\hline
\end{tabular}

Values are presented as mean \pm standard deviation or number (\%).

${ }^{*}$ Compared with nondrinkers by t-test and chi-square test. ${ }^{\dagger} 1$ drink $=14 \mathrm{~g}$ of alcohol. 
Table 3. Risk for abnormal gamma-glutamyl transpeptidase expression according to weekly drinking amount in flushers and non-flushers

\begin{tabular}{|c|c|c|c|c|}
\hline \multirow{2}{*}{ Variable } & \multirow{2}{*}{ P-value } & \multirow{2}{*}{ Odds ratio } & \multicolumn{2}{|c|}{ 95\% confidence interval } \\
\hline & & & Lower & Upper \\
\hline \multicolumn{5}{|c|}{ Flushers (drinks/wk) } \\
\hline Non-drinkers & & 1.000 & & \\
\hline$<4$ & 0.003 & 4.120 & 1.603 & 10.585 \\
\hline $4-8$ & $<0.001$ & 79.206 & 24.034 & 261.031 \\
\hline$\geq 8$ & $<0.001$ & 111.342 & 30.987 & 400.079 \\
\hline \multicolumn{5}{|c|}{ Non-flushers (drinks/wk) } \\
\hline Non-drinkers & & 1.000 & & \\
\hline$<4$ & 0.115 & 2.960 & 0.767 & 11.417 \\
\hline $4-8$ & $<0.001$ & 37.568 & 9.793 & 144.116 \\
\hline$\geq 8$ & $<0.001$ & 78.801 & 20.350 & 305.138 \\
\hline
\end{tabular}

By logistic regression with adjustment for age, smoking, menopause, and body mass index.

\section{DISCUSSION}

Based on the results of many studies, the guidelines of moderate or risky drinking amounts related to health have been suggested. The Western drinking standards, however, may be inappropriate for Koreans, because many of whom are physically smaller and deficient in ALDH2 compared to Westerners. Unfortunately, few studies have attempted to identify the appropriate drinking level for Koreans. Furthermore, there are hardly any studies focused on determining the appropriate drinking level for Korean women.

The present study has significant meaning because it bridges this gap in knowledge. It investigated the association of women's alcohol consumption with their risk of abnormal GGT expression. In addition, the current study further suggested that, depending on their facial flushing status after drinking, different levels of alcohol consumption may be associated with abnormal GGT expression in Korean women.

In this study, the weekly drinking amount associated with abnormal GGT expression in women without facial flushing after drinking was 4 drinks, which is the half of the men's drinking amount suggested by previous domestic study. Kim et al. ${ }^{18)}$ found that consuming 8.75 drinks or more was associated with abnormal GGT expression in Korean men without facial flushing after drinking. This is consistent with findings by Frezza et al. ${ }^{19)}$ that women are more affected by alcohol than men, because the blood alcohol level in women was higher when the same amount of alcohol was consumed, likely due to the higher body fat percentages and fewer alcohol metabolizing enzymes in women. Thus, abnormal GGT expression can be induced by a smaller amount of alcohol consumption in women than in men. In addition, the NIAAA's recommendation that women drink half the amount recommended for men seems to further support the results of the present study. ${ }^{15)}$

Another interesting result of the current study is that abnormal GGT expression was observed with $>4$ drinks in women
Table 4. Risk for abnormal gamma-glutamyl transpeptidase expression in flushers comparing with non-flushers

\begin{tabular}{|c|c|c|c|c|}
\hline \multirow{2}{*}{ Variable } & \multirow{2}{*}{ P-value } & \multirow{2}{*}{ Odds ratio } & \multicolumn{2}{|c|}{$95 \%$ confidence interva } \\
\hline & & & Lower & Upper \\
\hline Non-flushers (drinks/wk) & & 1.000 & & \\
\hline$<4$ & 0.001 & 3.867 & 1.786 & 8.374 \\
\hline $4-8$ & $<0.001$ & 57.277 & 24.430 & 134.285 \\
\hline$\geq 8$ & $<0.001$ & 104.871 & 42.945 & 256.091 \\
\hline
\end{tabular}

By logistic regression with adjustment for age, smoking, menopause, and body mass index.

without facial flushing, which is less than the moderate drinking amount ( $<7$ drinks) recommended for women by the NIAAA. ${ }^{15}$ ) This finding is considered to be consistent with the findings of a study by Kim et al. ${ }^{18)}$ in which abnormal GGT expression was induced in Korean men without facial flushing after 8.75 drinks, which is less than the moderate drinking amount (14 drinks) recommended for Western men by the NIAAA. ${ }^{15)}$ It is also in agreement with the findings of a study by Kim et al. ${ }^{20)}$ in which, in terms of the risk of hyperhomocysteinemia, they suggested alcohol consumption of $<8$ drinks for Korean men. This indicates that the moderate drinking amount for physically smaller Koreans should be less than the standard proposed by the NIAAA. ${ }^{15)}$

Unlike the non-flushing group, in the present study the risk of abnormal GGT expression increased in all drinking ranges of the flushing group compared to that in the nondrinking group. This is consistent with the findings of a study by Kim et al. ${ }^{18)}$ that showed that abnormal GGT expression in the flushing group was induced by smaller amounts of alcohol than in the nonflushing group. Similarly, another study by Kim et al. ${ }^{20)}$ showed that the risk of hyperhomocysteinemia in the flushing group was only decreased with the consumption of $<4$ drinks, whereas the risk in the non-flushing group decreased with the consumption of $<8$ drinks. Moreover, the result of the current study are further supported by those of Jung et al. ${ }^{21)}$ in which the hypertension risk increased at $>4$ drinks in the flushing group, whereas the risk increased at $>8$ drinks per week in the nonflushing group. A marked increase in the risk of abnormal GGT expression in the flushing compared to that in the non-flushing group can be interpreted as a greater influence of unmetabolized acetaldehyde in subjects with facial flushing.

ALDH polymorphism that causes facial flushing after drinking is commonly seen in Asians, including Koreas. Despite the potential risks associated with drinking, many of these people drink. From the clinician's point of view, this is an important social problem in Korea. The drinking culture in Korea values the sense of belonging and friendship obtained through drinking communally. Therefore, the Korean clinical environment should emphasize educating people about the adverse effects of excessive drinking and the various individual differences that may affect drinking outcomes, including facial flushing, 
when drinking.

This study had some limitations. First, in this study, the facial flushing and non-flushing group dividing was based only on the questionnaire proposed by Yokoyama et al. ${ }^{17)}$ Second, the subjects were recruited from a single university hospital. Third, it was not a long-term follow-up study of drinking patterns, but a cross-sectional study. Fourth, the small number of subject drinking more than 4 drinks per week might cause high OR and wide $95 \% \mathrm{CI}$ in logistic regression.

Despite these limitations, the present study is significant, as few similar studies have been conducted. Our result suggest that the extent to which drinking in Korean women contributes to the risk of abnormal GGT expression can vary depending on the presence of facial flushing. Therefore, it is necessary to consider the facial flushing status after drinking as well the amount of alcohol consumed when consulting with patients who drink.

\section{CONFLICT OF INTEREST}

No potential conflict of interest relevant to this article was reported.

\section{REFERENCES}

1. Crabb DW. Ethanol oxidizing enzymes: roles in alcohol metabolism and alcoholic liver disease. Prog Liver Dis 1995;13:151-72.

2. Crabb DW, Matsumoto M, Chang D, You M. Overview of the role of alcohol dehydrogenase and aldehyde dehydrogenase and their variants in the genesis of alcohol-related pathology. Proc Nutr Soc 2004;63:4963.

3. Ehrig T, Bosron WF, Li TK. Alcohol and aldehyde dehydrogenase. Alcohol Alcohol 1990;25:105-16.

4. Yin SJ, Liao CS, Chen CM, Fan FT, Lee SC. Genetic polymorphism and activities of human lung alcohol and aldehyde dehydrogenases: implications for ethanol metabolism and cytotoxicity. Biochem Genet 1992; 30:203-15.

5. Harada S, Misawa S, Agarwal DP, Goedde HW. Liver alcohol dehydrogenase and aldehyde dehydrogenase in the Japanese: isozyme variation and its possible role in alcohol intoxication. Am J Hum Genet 1980; 32:8-15.

6. Ewing JA, Rouse BA, Pellizzari ED. Alcohol sensitivity and ethnic background. Am J Psychiatry 1974;131:206-10.

7. Wilson JR, McClearn GE, Johnson RC. Ethnic variation in use and ef- fects of alcohol. Drug Alcohol Depend 1978;3:147-51.

8. Wolff PH. Ethnic differences in alcohol sensitivity. Science 1972;175: 449-50.

9. Shibuya A, Yasunami M, Yoshida A. Genotype of alcohol dehydrogenase and aldehyde dehydrogenase loci in Japanese alcohol flushers and nonflushers. Hum Genet 1989;82:14-6.

10. Heo EJ, Kim MS, Kim KK. Drinking state and problem in women of some area. J Korea Community Health Nurs Acad Soc 2001;15:202-15.

11. Jang SO, Jung EA. Sex differences in drinking behavior and sex role expectations. J Soc Sci 2008;12:89-106.

12. Lee MK. Psychosocial factor associated drinking. J Korean Psychol 1993; 12:165-79.

13. Allen JP. Assessment of alcohol problems: an overview [Internet]. Bethesda (MD): National Institute of Health; 2004 [cited 2016 Jan 14]. Available from: http://pubs.niaaa.nih.gov/publications/assessingalcohol/ overview.htm.

14. Kyle UG, Schutz Y, Dupertuis YM, Pichard C. Body composition interpretation: contributions of the fat-free mass index and the body fat mass index. Nutrition 2003;19:597-604.

15. Rockville MD. A poket guide for alcohol screening and brief intervention [Internet]. Bethesda (MD): National Institutes of Health; 2005 [cited 2013 Jan 29]. Available from: http://pubs.niaaa.nih.gov/publications/practitioner/clinicians/guide2005/guide.pdf.

16. American Psychiatry Association. Diagnostic and statistical manual of mental disorder. 5th ed. New York (NY): American Psychiatry Association; 2014.

17. Yokoyama A, Muramatsu T, Ohmori T, Kumagai Y, Higuchi S, Ishii H. Reliability of a flushing questionnaire and the ethanol patch test in screening for inactive aldehyde dehydrogenase-2 and alcohol-related cancer risk. Cancer Epidemiol Biomarkers Prev 1997;6:1105-7.

18. Kim SG, Kim JS, Kim SS, Jung JG, Yun SJ, Kim EC. Relationships between the level of alcohol consumption and abnormality in biomarkers according to facial flushing in Korean male drinkers. Korean J Fam Med 2013;34:123-30.

19. Frezza M, di Padova C, Pozzato G, Terpin M, Baraona E, Lieber CS. High blood alcohol levels in women: the role of decreased gastric alcohol dehydrogenase activity and first-pass metabolism. N Engl J Med 1990; 322:95-9.

20. Kim EC, Kim JS, Jung JG, Kim SS, Yoon SJ, Ryu JS. Effect of alcohol consumption on risk of hyperhomocysteinemia based on alcohol-related facial flushing response. Korean J Fam Med 2013;34:250-7.

21. Jung JG, Kim JS, Kim YS, Oh MK, Yoon SJ. Hypertension associated with alcohol consumption based on the facial flushing reaction to drinking. Alcohol Clin Exp Res 2014;38:1020-5. 